\title{
Conquistando com o Resto: Um Jogo Para o Ensino de Conceitos de Divisão
}

\author{
Wilk Oliveira dos Santos ${ }^{12}$, Jário J. dos Santos Júnior ${ }^{2}$, Daniel Borges F. da Silva ${ }^{2}$, \\ Ig Ibert Bittencourt ${ }^{2}$, Clovis Gomes da Silva Junior ${ }^{1}$ \\ ${ }^{1}$ Universidade de Pernambuco, Campus Garanhuns (UPE) Av. Cap. Pedro \\ Rodrigues, 105 - São José, CEP 55.294-902 - Garanhuns - PE - Brasil \\ ${ }^{2}$ Núcleo de Excelência em Tecnologias Sociais (NEES) - Instituto de Computação - \\ Universidade Federal de Alagoas (IC-UFAL) Av. Lourival Melo Mota, S/N - Tabuleiro \\ dos Martins, CEP 57072-900 - Maceió - AL - Brasil \\ \{wos, jjsj, dbfs, ig.ibert\}@ic.ufal.br, clovis.gomes@upe.br
}

Resumo. É sabido que os jogos digitais vêm ganhando espaço nos mais diferentes aspectos sociais, inclusive no contexto escolar, como mecanismo de apoio ao processo de ensino e aprendizagem. Neste sentido, este artigo descreve o jogo "Conquistando com Resto", um jogo para o ensino de conceitos de divisão, desenvolvido por meio do processo de Virtualização de Jogos. O artigo apresenta ainda o processo de desenvolvimento e avaliação deste jogo, que pode ser executado em plataformas móveis ou em desktops.

\begin{abstract}
We know how digital games were win space in different contexts, including educational context, with mechanism of support teaching and learning process. In this sense, this paper present the game "Conquistando com o Resto", an educative game for teaching of division, developed for Virtualization Game Process. The paper present also the development process and evaluate of game. The game can executable in mobile devices and computers desktop.
\end{abstract}

\section{Introdução}

A sociedade contemporânea é caracterizada pelo uso cada vez mais frequente das tecnologias digitais da informação e comunicação (TDIC) na organização das mais diferentes práticas sociais, como aponta Ribeiro (2012). Nesse contexto, o investimento em tecnologias e a presença das mesmas em salas de aula é cada vez maior. Comumente, encontram-se nas escolas, laboratórios de informática ou até mesmo com os próprios estudantes, dispositivos como notebooks, tablets, smartphones, entre outros.

Neste sentido, atualmente pesquisas demonstram uma série de benefícios em incluir os jogos digitais no processo ensino-aprendizagem, apontando possibilidades de ser um rico instrumento para a construção do conhecimento, transformando o ato de jogar em ato de aprender e ensinar, construindo os objetivos necessários para se alcançar a aprendizagem, como elucidado por Medeiros et al. (2013).

No entanto, observam-se nas discussões do uso de jogos na educação, que podem existir também fatos negativos, segundo Falkembach (2007) apude Medeiros et 


\section{CBIE-LACLO 2015}

Anais dos Workshops do IV Congresso Brasileiro de Informática na Educação (CBIE 2015)

al. (2013), mesmo um jogo bem projetado pode ter algumas desvantagens como: se não for bem aplicado perde o objetivo; nem todos os conceitos podem ser explicados por meio dos jogos; se o professor interferir com frequência, perde a ludicidade; e se o aluno for obrigado a jogar por exigência do professor, o aluno fica contrariado.

Ou ainda, experiências como as de Cabreira e Aquino (2006), que discursão sobre o processo de virtualização do saber, em uma perspectiva de substituição das atividades tradicionais, por atividades ligadas as tecnologias digitais, apontando inclusive que os professores, por vezes se sentem impotentes ao levar um jogo tradicional a sala de aula, e os estudantes não aderirem a atividade, estes estudantes, segundo Santos et al. (2013) se sentem mais atraídos por atividades ligadas as TDIC em detrimento aos meios tradicionais.

Com o objetivo de minimizar esta dificuldade, observam-se na literatura, trabalhos que tratam da Virtualização de Jogos para o ensino. De acordo com Santos et al. (2013), através desta técnica, é possível unir os princípios pedagógicos contidos nos jogos tradicionais, outrora usados de forma positiva no ensino, às novas mídias presentes no contexto social atual.

Neste contexto, este artigo objetiva apresentar o jogo "Conquistando com o Resto", outrora utilizado de forma positiva no ensino de Matemática. O jogo é composto por um tabuleiro estrategicamente numerado, de forma a propor uma serie de desafios para os estudantes. O jogo (virtualizado) pode ser executado em uma das seguintes plataformas móveis: Android, BlackBerry ou Windows Phone, além de plataformas desktop que executem sistemas Microsoft Windows.

O jogo faz parte de um projeto de pesquisa, ensino e extensão realizado entre os anos de 2012 e 2015 por estudantes de graduação, mestrado e doutorado, além de professores de Matemática, bem como profissionais da Computação, Pedagogia e Psicologia da Universidade de Pernambuco e da Universidade Federal de Alagoas. O texto apresenta ainda seu processo de desenvolvimento baseado no processo de Virtualização de Jogos, bem como sua avaliação.

Os resultados iniciais permitiram constatar-se a importância trabalhar com uma equipe multidisciplinar, capaz de auxiliar no processo do desenvolvimento do jogo. Através da análise de desempenho, observou-se que o jogo funcionou de forma correta nos dispositivos usados pelos estudantes. Analisando a interface da aplicação, concluiuse que as cores foram utilizadas corretamente e os ícones relacionados aos botões foram facilmente entendidos, bem como por meio da avaliação pedagógica, que seus objetivos pedagógicos foram atingidos (eg. Santos et al. (2014) e Santos et al. (2015)).

\section{2. "Conquistando com o Resto": Cenário de Uso}

O jogo "Conquistando com o Resto" consiste em um tabuleiro com 48 casas, numeradas de forma não sequencial, como apresentado na Figura 1. Os jogadores começam o jogo na casa 43 (primeira casa do tabuleiro) e jogam sequencialmente um dado em formato de cubo (um jogador por vez) dividindo o valor da casa em que se encontra (incialmente casa 43) pelo valor que for obtido no dado, em seguida avança exatamente o quantitativo de casas correspondente ao resto desta divisão.

Figura 1 - Conquistando com Resto (versão tradicional/manual) 
CBIE-LACLO 2015

Anais dos Workshops do IV Congresso Brasileiro de Informática na Educação (CBIE 2015)

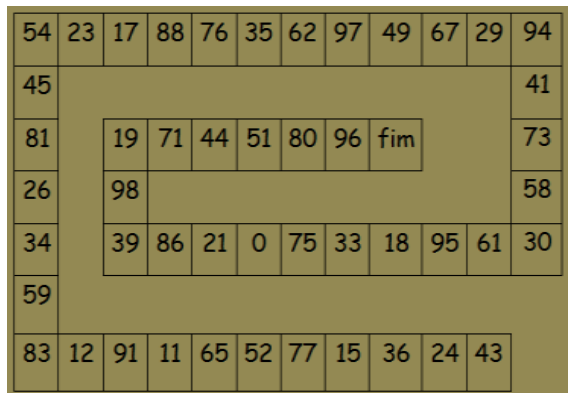

Este jogo era usado (em sua versão tradicional) como mecanismo de apoio ao ensino de divisão, propiciando aos estudantes uma forma lúdica e divertida de compreender de forma implícita ao jogo, determinados conceitos fundamentais a operações de divisão. Por meio de sua versão digital ora apresentada, o mesmo pode ser usado por estudantes e professores, não somente no contexto de sala de aula, podendo ser jogado de forma individual em duplas ou até mesmo em equipes, por meio de plataformas móveis ou desktops.

\section{Processo de Virtualização}

O Processo de Virtualização de Jogos é compreendido, como o processo pelo qual, os jogos tradicionais, são recriados em versões digitais, de maneira que não percam seus aspectos pedagógicos e psicopedagógicos, que os levaram a ser utilizados de forma positiva como ferramenta de auxilio ao processo de ensino e aprendizado da disciplina em questão, como salienta Santos et al. (2014).

Tal processo deve ocorrer por meio de equipe multidisciplinar, com a participação de professores da disciplina em questão além de profissionais da área de Psicologia, responsáveis por analisar e propor soluções para facilitar a interação dos estudantes e professores com os jogos, bem como manter os conceitos pedagógicos e psicopedagógicos contidos na versão tradicional do jogo, além de profissionais de Pedagogia e Computação, responsáveis por atrelar os aspectos pedagógicos aos aspectos computacionais do jogo, como aconselha Santos et al. (2013). Neste contexto, o desenvolvimento desde jogo, ocorreu por meio do processo de Virtualização de Jogos.

\subsection{Processo de Virtualização do Jogo Conquistando com Resto}

No que cerne o desenvolvimento (Processo de Virtualização), do jogo "Conquistando com o Resto", a priori, o mesmo foi analisado por professores da disciplina de Matemática, enfatizando como ocorre o uso do mesmo em sala de aula e destacando suas estruturas matemáticas.

Posteriormente, profissionais de Psicologia puderam definir como deveria ficar a versão digital do jogo, contemplando uma mecânica que permitisse um uso agradável e satisfatório por parte de estudantes e professores, ao mesmo tempo, que mantivesse os aspectos, pedagógicos e psicopedagógicos da versão original/tradicional do jogo, fundamentais para que a versão digital do mesmo seja usada como recurso de apoio ao processo de ensino e aprendizagem da disciplina de Matemática (eg. Santos et al. 2014).

Na sequência, ocorreu a escolha do software para desenvolvimento do mesmo, que partiu da análise de quatro motores de desenvolvimento de jogos digitais. Esta 
análise permitiu que pudesse perceber as limitações de cada ferramenta, como tipos de jogos produzidos, plataformas suportadas, etc. Esta análise é apresentada no Quadro 1, que apresenta as ferramentas analisadas.

\begin{tabular}{|l|l|l|l|}
\hline \multicolumn{5}{|c|}{ Ferramentas Analisadas } \\
\hline Ferramenta & Tipos de Jogos & \multicolumn{1}{|c|}{ Plataformas Suportadas } & Desenvolvedora \\
\hline Game Maker $^{l}$ & 2D & Windows, Android, IOS, Ubuntu e Mac OS X & YoYo Games \\
\hline Construct 2 $^{2}$ & 2D & $\begin{array}{l}\text { Windows, Windows Ohone, Android, IOS e } \\
\text { BlackBerry }\end{array}$ & Scirra \\
\hline Unity $^{3}$ & 2D e 3D & $\begin{array}{l}\text { Windows, Windows Phone, BlackBerry 10, PS2, Ayatana } \\
\text { PS3 e Web }\end{array}$ & $\begin{array}{l}\text { Windows, Android, IOS, Mac OS X, PS2, PS3, Epic Games } \\
\text { PS4 }\end{array}$ \\
\hline$U^{4} K^{4}$ & 2D e 3D & Enimes \\
\hline
\end{tabular}

\section{Quadro 1 - Ferramentas Analisadas}

Em função das observações relatadas pelos professores de Matemática e pelos profissionais de Psicologia nas fases anteriores do trabalho, bem como pela necessidade de um desenvolvimento do game em 2D para plataforma Windows e futura exportação para plataformas móveis, fazendo preferencialmente uso de programação drag-and-drop baseada em eventos, como sugerido por estes profissionais, optou-se por trabalhar com a segunda ferramenta a ser analisada (Construct 2), que dispõe ainda de uma documentação extensa e gratuita.

Santos et al. (2015) salienta que tal ferramenta oportunizou uma maior facilidade no desenvolvimento, ao mesmo tempo em que alta qualidade nos aspectos computacionais do mesmo. Usou-se ainda, na fase de desenvolvimento, o software Corel Draw ${ }^{5}$, programa de desenho vetorial bidimensional para design gráfico, que nos permitiu criar as imagens usadas no jogo.

Depois de escolhidas às ferramentas a serem usadas no desenvolvimento do jogo, deu-se inicio ao desenvolvimento do mesmo. Inicialmente foram criadas no software Corel Draw as imagens usadas no jogo (tabuleiro, dado, telas e botões em geral, etc.) que na sequência foram adicionadas ao software Construct 2 e organizada segundo os critérios estabelecidos nas fases anteriores, de modo a iniciar-se o trabalho de programação do jogo. $\mathrm{O}$ jogo foi dividido em três telas descritas a seguir:

- Tela Início: Na tela inicio (Figura 2), os jogadores tem sua primeira interação com o jogo, bem como podem escolher o percurso inicial que irão percorrer no jogo.

\section{Figura 2 - Tela de Início}

\footnotetext{
${ }^{1}$ Para mais informações, consultar: www.yoyogames.com

${ }^{2}$ Para maiores informações, consultar: www.scirra.com

${ }^{3}$ Para maiores informações, consultar: www.unity3d.com

${ }^{4}$ Para maiores informações, consultar: www.unrealengine.com/udk/

${ }^{5}$ Para maiores informações, consultar: www.corel.com
} 


\section{CBIE-LACLO 2015}

Anais dos Workshops do IV Congresso Brasileiro de Informática na Educação (CBIE 2015)

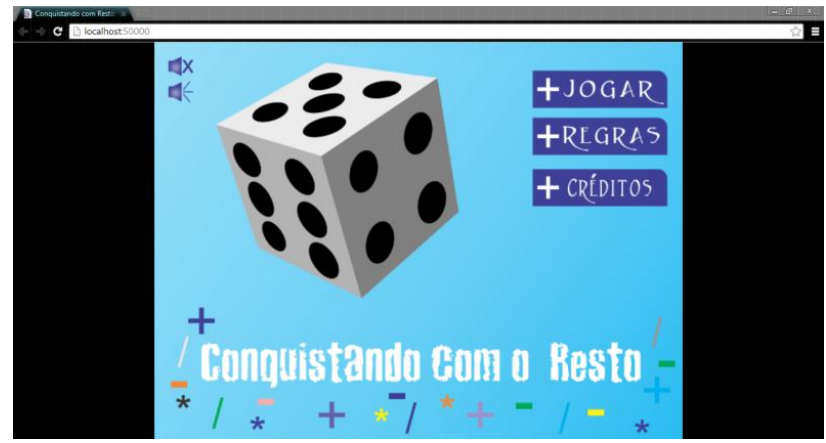

- Tela Regras: Nesta tela são apresentadas as regras do jogo, bem como exemplos que devem auxiliar os jogadores na execução do mesmo.

Figura 3 - Tela de Regras

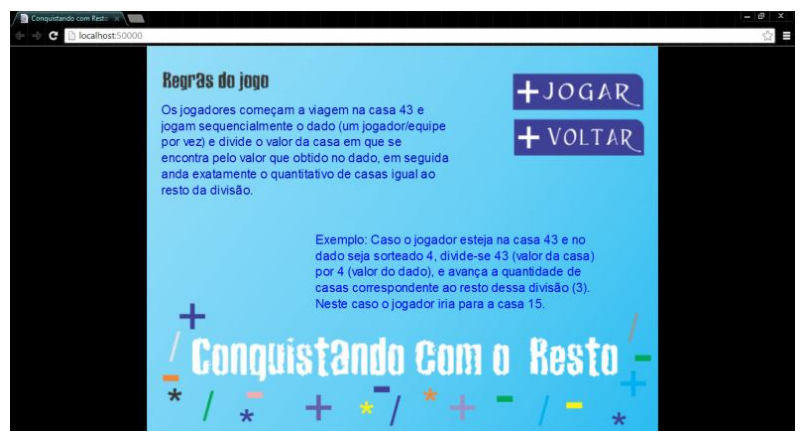

- Tela Jogo: Nesta tela é apresentado o jogo. Esta assume fundamental importância para o mesmo, pois é nela que se encontra o objeto principal do software desenvolvido, "o jogo".

Figura 4 - Tela do Jogo

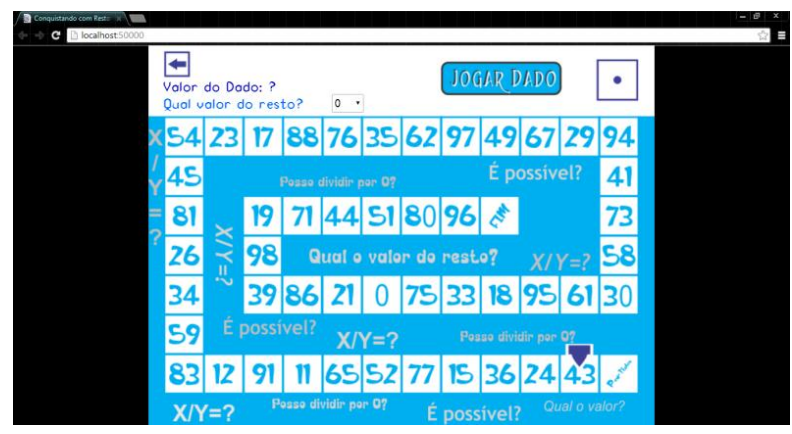

Depois de finalizado o desenvolvimento da primeira versão digital do jogo (Conquistando com o Resto 1.0), o mesmo foi submetido à avaliação por parte de estudantes e professores, caracterizando uma avaliação focada no cliente, e ao mesmo tempo focada em especialistas, a avaliação, é ainda focada tanto nos aspectos computacionais de interface do jogo, quanto nos aspectos pedagógicos $\mathrm{e}$ psicopedagógicos do mesmo, sendo esta avaliação, feita em aspectos quantitativos e aspectos qualitativos. 
CBIE-LACLO 2015

Anais dos Workshops do IV Congresso Brasileiro de Informática na Educação (CBIE 2015)

\section{Avaliação do Jogo}

O jogo ora apresentado foi avaliado de forma qualitativa e quantitativa em duas perspectivas, sendo elas computacional, no que tange a avaliação de aspectos ligados a interface gráfica e aspectos pedagógicos, no que se refere à análise dos aspectos matemáticos abordados no jogo, como mostra Santos et al. (2015). Neste sentido, para a realização desta avaliação foi escolhido um grupo de 10 estudantes (entre 40) de forma aleatória, em uma turma de $6^{\text {a }}$ série (quinto ano) locada em uma escola publica estadual do Agreste pernambucano, a turma foi escolhida de acordo com os descritores da que contemplavam os assuntos abordados no jogo.

$\mathrm{Na}$ avaliação da interface, os estudantes responderam a um total de oito questões (assertivas) definidas pelo profissional de IHC, as questões envolveram itens de interface relacionados à aprendizagem, memorização e conforto visual. Optou-se por realizar esta avaliação de forma quantitativa, fazendo uso da escala de Likert, que de acordo como Fialho (2007) permite mostrar qual o grau de concordância e/ou discordância do usuário em relação aos elementos funcionais de determinado objeto.

A avaliação dos aspectos pedagógicos matemáticos foi realizada de forma qualitativa, neste sentido, as folhas de rascunho entregue aos estudantes foram analisadas pelo professor de Matemática, com o intuito de interpretar matematicamente as anotações feitas pelos estudantes, de acordo com a proposta do jogo, o mesmo foi ainda responsável por aferir uma série de informações concernentes à validação da proposta do jogo.

Em ambas as avaliações o jogo foi validado de forma positiva, sendo considerado apto para ser usado como mecanismo de apoio ao processo de ensino e aprendizagem da disciplina de Matemática. Os resultados desta avaliação são mostrados em Santos et al. (2015).

\section{Considerações Finais}

Como afirma Alves (2005), Tarouco (2005) e Mattar (2010) entre outros, o uso de jogos já esta cunhado como um artefato que se bem desenvolvido e bem aplicado, auxilia de forma grandiosa os processos de ensino e aprendizagem, sendo colocado como uma alternativa capaz de motivar, engajar, avaliar, ou mesmo preparar os estudantes, não somente no cerne dos conteúdos vislumbrados nos currículos escolares, mas também em toda a vida cotidiana dos mesmos.

É notório também, que existe uma série de contrapontos nos aspectos relacionados ao desenvolvimento e aplicação destes jogos, sabe-se que se os mesmo não forem desenvolvidos e aplicados de acordo com metodologias que promovam o ensino e aprendizagem, os resultados poderão não ser satisfatórios. Ou ainda, quando os professores levam a sala de aula, jogos tradicionais, que fujam da realidade digital dos estudantes, não terão o seu convite ao jogo aceito pelos mesmos, muitas vezes causando um sentimento de frustração. 


\section{CBIE-LACLO 2015}

Anais dos Workshops do IV Congresso Brasileiro de Informática na Educação (CBIE 2015)

O jogo, ora descrito, apresenta-se como uma possibilidade para que professores e estudantes possam usufruir de um ambiente lúdico e interativo, mantendo-se os aspectos pedagógicos e psicopedagógicos, presentes na versão tradicional do jogo, e ao mesmo tempo, atrelado às novas mecânicas de jogos digitais, proporcionado uma união entre o tradicional e o digital, conseguido por meio do processo de Virtualização de Jogos. Os testes prévios realizados no jogo permitem fazer inferência a determinadas falhas que ocorreram ao longo de seu processo de desenvolvimento, que foram observadas e corrigidas ao longo deste processo.

Diante da pesquisa realizada, foi possível observar que o jogo ora apresentado, pode ser usado como mecanismo de apoio ao processo de ensino e aprendizagem de conceitos de divisão, bem como que o processo de Virtualização de jogos, pode ser usado para o desenvolvimento de jogos capazes de serem usados de forma positiva no contexto educativo. Desafia-se como trabalhos futuros o desenvolvimento de novas versões para o jogo, bem como uma versão multiplayer, além de submeter o mesmo a novas avaliações. Uma versão (desktop) de teste para deste jogo pode ser encontrada no seguinte link: http://migre.me/rfluR

\section{Referências}

Buchinger, D; Hounsell, M.S; Dias, C (2012) "Colaboratividade em um Jogo Eletrônico para Ensino sobre Dengue”, In: Anais do XXIII Simpósio Brasileiro de informática na Educação (SBIE), Rio de Janeiro - RJ, Brasil.

Cabreira, L. G.; Aquino, O. R. (2006) "Jogos eletrônicos - a virtualização do brincar na perspectiva dos professores de $3^{\mathrm{a}}$ e $4^{\mathrm{a}}$ séries do ensino fundamental I deuma escola particular de Maringá/PR", In: Educação em Revista $7^{\text {a }}$ ed., p. 85-102, São Paulo.

Medeiros, T.J.; Da Silva, T. R.; Aranha, E. H. S Ensino de programação utilizando jogos digitais: uma revisão sistemática da literatura. In: Revista Novas Tecnologias na Educação (RENOTE), v.11, n.2, 2013.

Reinoso, L.F; Neto, C.B; Lopes, L.C.L (2012) "Principais Características dos Games para serem Inseridos como Ferramenta Educacional", Revista Novas Tecnologias na Educação (RENOTE), p. 42-43, Porto Alegre - RS, Brasil.

Ribeiro, A., L. (2012) "Jogos digitais online: ampliando o(s) Letramento(s) na sala de aula" In: Anais do IV Simpósio Hipertexto e Tecnologias na Educação (SHTE), Recife - PE, Brasil.

Sá, E. J. V; Teixeira, J.S.F; Fernandes, C.T (2007) "Design de atividades de aprendizagem que usam Jogos como princípio para Cooperação", In: XVIII Simpósio Brasileiro de Informática na Educação (SBIE), São Paulo - SP, Brasil.

Santos, W. O.; Silva Junior, C. G.; Barros, F. L. P. (2013) "Processo de virtualização de jogos matemáticos tradicionais, para uso como ferramenta de auxilio ao processo de ensino e aprendizagem em escolas do agreste de Pernambuco", In: Anais do V Encontro Anual de Tecnologia da Informação (EATI), p. 312-316, Frederico Westphalen - RS.

Santos, W. O.; Silva Neto, S. R.; Silva Junior, C. G. (2013) "Uso de Games no ensino da Matemática. Uma proposta de virtualização dos jogos tradicionais, para uso como 
mecanismo de apoio ao processo de ensino e aprendizagem", In: Anais do V Simpósio Hipertexto e Tecnologias na Educação (SHTE), Recife - PE, p. 216.

Santos, W. O.; da Silva, A. P.; Silva Junior, C. G. (2014) "Conquistando com o Resto: Virtualização de um Jogo para o Ensino de Matemática”. In: Anais do XXV Simpósio Brasileiro de Informática na Educação (SBIE). Dourados - MT p. 317-321.

Santos, W. O., Silva Neto, S. R., Silva Junior, C. G. (2015). "Processo de Virtualização de Jogos para Uso como Mecanismo de Apoio ao Processo de Ensino e Aprendizagem da Disciplina de Matemática”. In: Anais do XI Seminário Jogos Eletrônicos Educação e Comunicação (SJEEC). Salvador - BA, p. 109-117.

Santos, W. O., Silva Neto, S. R., I., I., Bittencourt, Silva Junior, C. G. (2015) "Avaliação de Jogos Educativos: Uma Abordagem no Ensino de Matemática". In: Anais do XXVI Simpósio Brasileiro de Informática na Educação (SBIE). Maceió - AL.

Silva Neto, S. R.; Santos, W. O; Silva Junior, C. G. (2013) "Games no ensino da Matemática. Processos de Virtualização de Jogos para uso entre estudantes e professores da região Agreste do estado de Pernambuco", In: Anais do V Simpósio Hipertexto e Tecnologias na Educação (SHTE), Recife - PE, p. 216. 